\title{
CATEGORIAS ONTOLÓGICAS E AFIXOS TAXONÔMICOS EM LÍNGUAS AMERÍNDIAS
}

\section{CATEGORÍAS ONTOLÓGICAS Y AFICIONES TAXONÓMICAS EN LENGUAS AMERINDIANAS}

\section{ONTOLOGICAL CATEGORIES AND TAXONOMIC AFFIXES IN AMERINDIAN LANGUAGES}

\author{
Autor 1:Evandro de Sousa Bonfim \\ https://orcid.org/0000-0002-0459-928X \\ Titulação: Doutor em Antropologia \\ Cargo: Docente colaborador do Mestrado Profissional em Linguística e Línguas Indígenas \\ (PROFLLIND) do Museu Nacional-UFRJ. \\ Universidade Federal do Rio de Janeiro, Departamento de Antropologia \\ Rio de Janeiro - Rio de Janeiro - Brasil \\ E-mail: evandrobonfim@hotmail.com \\ Autor 2:Maycon Silva Aguiar \\ https://orcid.org/0000-0003-2998-865X \\ Titulação: Mestre em Linguística \\ Cargo: Docente colaborador da Especialização em Linguística e Línguas Indígenas do \\ Museu Nacional-UFRJ \\ Universidade Federal do Rio de Janeiro - Departamento de Antropologia \\ Rio de Janeiro - Rio de Janeiro - Brasil \\ E-mail: mayconsilvaaguiar@mn.ufrj.br
}


BONFIN, E.S; AGUIAR, M. S. .Categorias ontológicas e afixos taxonômicos em línguas ameríndias. R. Científica UBM - Barra Mansa (RJ), ano XXVI, v. 23, n. 45, 2 . Sem. 2021 p. 26-36.

ISSN 1516-4071

\section{RESUMO}

Neste artigo, que contém conclusões preliminares de nossa pesquisa, focamos a categoria modificador no bojo de sistemas de classificação de línguas ameríndias. Para tanto, analisaremos o escopo de elementos modificadores nas línguas Xavante e Guajajara e na variante Mbya de Guarani. A função semântica de alguns modificadores é semelhante à dos descritos por Viveiros de Castro $(1996,2002)$ para a língua Yawalapiti, como é o caso de morfemas como -ete. Mais especificamente, apontaremos que essas marcas linguísticas abrangem elementos abstratos e concretos e obedecem a uma lógica taxionômica particular, configurando o que denominamos modificadores ontológicos, conceito que estamos em vias de definir.

Palavras-chave: Modificadores ontológicos. Línguas ameríndias. Língua e cosmologia. Língua e ontologia.

\section{RESUMEN}

En este artículo, que contiene conclusiones preliminares de nuestra investigación, nos centramos en la categoría de modificadores dentro de los sistemas de clasificación de lenguas amerindias. Por tanto, analizaremos el alcance de los elementos modificadores en las lenguas Xavante y Guajajara y en la variante Mbya del Guaraní. La función semántica de algunos modificadores es similar a las descritas por Viveiros de Castro $(1996,2002)$ para el lenguaje Yawalapiti, como es el caso de morfemas como -ete. Más concretamente, señalaremos que estas marcas lingüísticas abarcan elementos abstractos y concretos y obedecen a una lógica taxonómica particular, configurando lo que llamamos modificadores ontológicos, concepto que estamos por definir.

Palavras clave: Modificadores ontológicos. Lenguas amerindias. Lenguaje y cosmología. Lenguaje y ontología.

\section{ABSTRACT}

In this article, which contains preliminary conclusions from our research, we focus on the nonlimited modifier category of American language classification systems. For this, we will analyze modifying elements of Xavante and Guajajara languages and Mbya variant of Guarani. A semantic function of some modifiers is like two described by Viveiros de Castro $(1996,2002)$ for the Yawalapiti language, as in the case of morphemes like -ete. More specifically, we will point out that these linguistic marks include abstract and concrete elements and obey a particular taxonomic logic, configuring what we call ontological modifiers, a concept that we are in the process of definition.

Keywords: Ontological modifiers. Amerindian languages. Language and cosmology. Language and ontology.

\section{INTRODUÇÃO}

Mais do que itens lexicais que podem ser listados isoladamente, as categorias ontológicas ameríndias se tangenciam de forma sistêmica, estabelecendo relações de oposição, de variação e de transformação no interior de cada táxon - unidade taxonômica. Basicamente, dois critérios são relevantes para a classificação dos elementos nominais das línguas ameríndias em unidades taxonômicas: a definição semântica do elemento nominal (ser, cor, organização do mundo espiritual); e o tipo de modificador que se afixa ao elemento nominal. 
BONFIN, E.S; AGUIAR, M. S. .Categorias ontológicas e afixos taxonômicos em línguas ameríndias. R. Científica UBM - Barra Mansa (RJ), ano XXVI, v. 23, n. 45, 2 . Sem. 2021 p. 26-36.

ISSN 1516-4071

A descrição da marcação linguística com classificadores, em conjunto com o trabalho etnográfico de descrição do cotidiano e de apreciação do pensamento mítico, recupera a articulação entre as noções semânticas que compõem as paisagens cosmológicas indígenas. Ainda que não defendamos uma subordinação da linguagem ao sistema cultural em que se inserem os indivíduos, é inegável que, em alguma medida, as línguas ameríndias refletem a cosmologia de seus povos ${ }^{1}$.

Diferentes trabalhos etnológicos apontam que a dinâmica dos sistemas classificatórios ameríndios se manifesta semanticamente e morfologicamente, como é o caso da análise de Viveiros de Castro (1996, 2002) de morfemas modificadores em Yawalapiti, língua Aruak falada no Alto Xingu. Para o autor, modificadores são "dispositivos semânticos cuja função seria estabelecer a distância metonímica ou a diferença metafórica entre protótipo ideal e fenômeno atual” (2002, p. 28). Os sufixos -kumã, -rúru, -mína e -malú desempenhariam esse papel em Yawalapiti. Ao serem afixados a nomes de animais, de plantas e de categorias sociais, modificariam a configuração característica da espécie denotada pelo nome.

Nesse sentido, o processo de modificação definiria, como táxon ou referente básico, o nome que receberá o afixo, que se transforma em uma categoria taxonômica; e criaria subtipos que guardam variadas qualidades de relações entre si, as quais podem ser expressas por noções gramaticais (como é caso de -kumã, que indica grau e se destina a versões monstruosas e/ou superiores do táxon) e por noções lexicais (como é o caso da oposição falso/verdadeiro entre malú e -rúru, respectivamente).

Portanto, considerando que os morfemas classificadores dispõem os seres em gradientes, evidenciando a distância das diferentes versões derivadas em relação ao táxon representado pela raiz nominal, tratá-los-emos como modificadores ontológicos: morfemas que, no plano gramatical, funcionam como classificadores; e que, no plano cosmológico, introduzem as categorias subjacentes ao pano de fundo cultural.

\section{DOS MODIFICADORES AOS MODIFICADORES ONTOLÓGICOS}

\footnotetext{
${ }^{1}$ A relação entre linguagem, pensamento e cultura é um campo de pesquisas fértil. Duas grandes teses antagônicas estão presentes nesse contexto: de um lado, há a ideia de que a linguagem é um subproduto da cultura e uma lente que se interpõe entre o indivíduo e a realidade; de outro, há a ideia de que a linguagem e a cultura são estruturas independentes, devendo ser descritas, portanto, de maneira particular. Neste trabalho, não acatamos nem uma nem outra perspectiva. Em vez disso, preferimos assumir uma posição mais cautelosa e mais sensata: não hierarquizamos linguagem e cultura, mas assumimos que mantêm algum grau de relacionamento e que, por isso, afetam-se mutuamente. Se não avançamos quanto à definição da precedência da cultura à linguagem (ou da linguagem à cultura), não adotamos, por outro lado, suposições que pouco contribuem com a descrição de nosso objeto.
} 
BONFIN, E.S; AGUIAR, M. S. .Categorias ontológicas e afixos taxonômicos em línguas ameríndias. R. Científica UBM - Barra Mansa (RJ), ano XXVI, v. 23, n. 45, 2 . Sem. 2021 p. 26-36.

O escopo dos modificadores costuma estender-se a instâncias em que, aparentemente, haveria pouco lugar para tematizações ontológicas, como acontece com os termos que designam cores. Contudo, Bonfim e Quintino (2013) demonstram que a oposição entre i’pré (vermelho) e i’udzé (demais cores) está presente no léxico cromático da língua Xavante e, ao mesmo tempo, é uma característica importante da cosmologia desse povo. De acordo com os autores, os Xavantes concebem a vida social como impregnada da cor vermelha, enquanto, no exterior da aldeia, predomina a cor i'udzé, que inclui matizes de verde, de azul e de amarelo ${ }^{2}$.

No léxico Xavante, o papel de modificador cabe ao termo $i$ 'a, que corresponde à ideia de branco, tomado, nesse contexto, como não cor. No entanto, afastando-nos da proposta de Viveiros de Castro (1996, 2002), preferimos tratar esse tipo de modificador como ontológico, especificação que nos parece capturar a possibilidade de que esses itens modularizem os itens nominais a que se afixam de um modo tão particular.

Assim, os modificadores ontológicos podem ser intensificadores $\mathrm{e}$ despotencializadores. Por exemplo, os efeitos despotencializadores da não cor Xavante podem ser observados no modo como o morfema i'a deriva novos termos de cores no léxico de Xavantes bilíngues, conforme apontam os dados seguintes.
(1) i’pré'a
'laranja'
(2) i'udze'a
'amarelo'

Nesses dados, i'a atua como um formativo que, ao se juntar a i'pré e a i'udzé (os dois protótipos de cores em Xavante), deriva as cores laranja e amarelo, respectivamente. Porém, mais do que novas cores, laranja (i'préa) e amarelo (i'udzé'a) são subtipos das cores de referência: laranja é "menos vermelho"; e amarelo é "menos todas as outras cores". As traduções tentam capturar uma restrição da cosmologia Xavante: sendo a não cor, $i$ ' $a$ não pode ser combinada com i'pré e com i'udzé, ao contrário do que seria esperado no processo ocidental de obtenção de cores.

Em ambos os exemplos, a modificação de $i$ 'a retira parte da potência dos elementos aos quais se afixa. No caso do primeiro, por degradá-lo em uma espécie de vermelho menos forte, o laranja; e, no do segundo, por eliminar a polivalência da categoria, restringindo i'udzé a apenas uma de suas possibilidades de realização, o amarelo, entendemos que o comportamento

2 Aparentemente, a oposição entre i’pré (vermelho) e i’udzé (demais cores) contradiz a famosa hipótese de Berlin e Kay (1965), de acordo com a qual a percepção cromática humana seria guiada por universais. 
BONFIN, E.S; AGUIAR, M. S. .Categorias ontológicas e afixos taxonômicos em línguas ameríndias. R. Científica UBM - Barra Mansa (RJ), ano XXVI, v. 23, n. 45, 2 . Sem. 2021 p. 26-36.

ISSN 1516-4071

de i'a respeita à obrigação de isolar, artificialmente, elementos cromáticos que atuem em conjunto. Portanto, em vez de desaparecerem, i’pré e i'udzé se apresentam como outras versões de si mesmos.

Nos dados seguintes, veremos que os termos cromáticos apresentam dois comportamentos sintáticos particulares, que servem tanto para reforçar a proposição de modificadores ontológicos quanto para evidenciar a importância do léxico cromático em relação à sociocosmologia Xavante.

(3) Ãhã sirãrã-hã i -pré

DEM flor -ENF REL-vermelho

(4) i -’pré -du i - rã -pré

REL-vermelho REL-cabeça-vermelha

(5) ni wa -hã ihi i -séré-`a

ninguém-ENF velho REL-cabelo-branco

(6) ritéi wa-hã i -séré i -rãdö

rapaz -ENF REL-cabelo REL-escuro
'Esta flor é vermelha'

'O homem adulto tem cabeça vermelha'

'Gente velha tem cabelo branco'

'Moço tem cabelo preto'

Assumindo o dado (3), entendemos que a cor pode, simplesmente, especificar um referente - nesse caso, atribui-se a qualidade "cor vermelha" a uma flor. Em Xavante, como em outras línguas indígenas, a cor não existe à parte daquilo que a porta. Por isso, o modificador ontológico vem acompanhado do prefixo relacional $i$-, que o indexa ao elemento nominal modificado.

Em (4), o processo é bastante diferente: no lugar de indexação, há incorporação do elemento nominal ao modificador ontológico, conferindo, assim, um caráter processual e transformacional que é próprio dos verbos ao termo cromático derivado. Nesse sentido, "a cabeça se avermelha" é uma das leituras possíveis de (4). Por outro lado, a característica de se avermelhar é uma propriedade que excede a nominação cromática, visto que recobre tudo o que é considerado belo e pleno (maduro) para os Xavantes, sendo o homem adulto que participa do 
BONFIN, E.S; AGUIAR, M. S. .Categorias ontológicas e afixos taxonômicos em línguas ameríndias. R. Científica UBM - Barra Mansa (RJ), ano XXVI, v. 23, n. 45, 2 . Sem. 2021 p. 26-36.

ISSN 1516-4071

warã, o conselho tribal, o representante prototípico dessa condição. Tal classe etária, i-pré-du, contém o modificador ontológico referente a vermelho ${ }^{3}$.

Nos exemplos (5) e (6), o que está em jogo é a passagem de jovem para velho, materializada na mudança da cor de cabelo. É notável que, embora exista uma oposição entre i'rãdö (escuro) e i'a (branco), isso acontece em relação a i'rã (claro). I'rãdö e i'rã são termos cromáticos responsáveis pela diferenciação de luminosidade, percepção que está associada à distinção das cores. Enquanto o cabelo de um jovem recebe o adjetivo "escuro", a aposição do termo para claro e a simples adjetivação não expressariam o processo de significação/transformação, envolvido no envelhecimento: perda de vitalidade por um processo que, mais do que indicar uma troca de cor, parece dizer respeito a certa perda de potência ou enfraquecimento de um jovem/cabelo escuro, resultando em um velho/cabelo branco. Trata-se, efetivamente, de modificação por decréscimo, por despigmentação, de modo que o branco se exibe, novamente, como não cor, em oposição a preto/escuro/jovem.

O princípio contrário ao caráter enfraquecedor da não cor pode ser descrito como intensificador e se visibiliza em termos extralinguísticos, considerando que o preto é a cor escolhida para salientar o vermelho nas pinturas corporais Xavante. Assim, no que se refere à estabilidade luminosa/cromática, os termos Xavante para escuro/claro e para preto/branco mantêm relações de sinonímia, enquanto, para os processos de modificação (dos corpos e das cores), somente i’u e, principalmente, i'a - a verdadeira partícula de desestabilização - são adequados.

\section{OS MODULARIZADORES E A FAMÍLIA TUPI-GUARANI}

Em seus trabalhos sobre os modificadores Yawalapiti, Viveiros de Castro (1996, 2002) aventa a possibilidade de que, entre os Jê e os Tupi-Guarani, sejam encontrados mecanismos classificatórios similares. Apesar disso, o autor não esclarece o que autoriza essa aproximação: perceba-se que, mesmo havendo certa confluência semântica, por exemplo, entre -ruru e -ete, que recobrem a noção de verdadeiro, a sua integração e a sua aplicação aos respectivos sistemas classificatórios revelam cosmologias distintas que devem, primeiramente, ser descritas e, apenas então, comparadas. No entanto, depreender pistas da organização ontológica TupiGuarani a partir de operações gramaticais classificatórias das línguas da família parece um exercício bastante produtivo. Para uma primeira abordagem, utilizaremos, aqui, exemplos do

${ }^{3}$ Seguindo esse raciocínio, a conhecida pintura vermelha Xavante apresenta significados profundos que podem ser identificados por meio de operações linguísticas. 
BONFIN, E.S; AGUIAR, M. S. .Categorias ontológicas e afixos taxonômicos em línguas ameríndias. R. Científica UBM - Barra Mansa (RJ), ano XXVI, v. 23, n. 45, 2 . Sem. 2021 p. 26-36.

ISSN 1516-4071

Guajajara, uma das cerca de 40 línguas da Família Tupi-Guarani, pertencente ao Tronco Tupi (RODRIGUES 1984; 1986).

Em Guajajara, o termo miar designa os animais, que se dividem em variadas classes. Algumas, como ipira (peixe) e wyrá (pássaro), têm inúmeros representantes, enquanto outras, como sokó (aves pernaltas pescadoras), contam com menos bichos. Diferentemente do Yawalapiti, o termo que nomeia as categorias mais abrangentes não diz respeito, necessariamente, a um representante prototípico que se atualizará, com afixos, para se ajustar ao mundo físico. Em vez disso, entendemos que as categorias são matrizes taxonômicas que guardam as características mais gerais dos seus elementos, cabendo a modificadores definir a especificidade dos itens a partir do conteúdo geral da classe.

(8a) wirá (pássaro)

(8b) wirá-ting (pássaro branco, garça)

(9a) mói (cobra)

(9b) mói-maraká (cascavel)

Como se pode extrair dos exemplos acima, as grandes classes de animais se opõem a partir de traços mais gerais: hábitos, formatos e habilidades (wirá:mói). Os traços distintivos servem para o interior das categorias e revelam o caráter icônico e motivado do signo linguístico tanto em Guajajara quanto em outras línguas Tupi-Guarani, nas quais a formação de palavras procura espelhar os elementos que particularizam o referente - a cor, no caso do pássaro; e o guizo similar ao maracá, na cascavel.

Contudo, existem situações que mobilizam outros recursos da língua. Por seu intermédio, podemos perceber mais detalhes de como atua o sistema classificatório nativo. Um caso conhecido é o da nomeação dos animais exógenos (trazidos pelo branco) (NORDENSKIÖLD, 1922). No lugar de adotar palavras europeias e de criar termos para designar os novos bichos, muitas línguas tomaram as espécies autóctones como modelo, o que se encaixa na discussão proposta por Viveiros de Castro.

Exemplo disso é a trajetória do cachorro doméstico, que costuma ser mais associado ao jaguar do que à categoria taxonômica maior à qual o felino pertence (VANDER VELDEN, 2004). Isso concede ao cachorro o estatuto de que pertence à posição do jaguar, que, então, passou a precisar de marcas adicionais para se diferenciar da nova espécie. Essas marcas 
BONFIN, E.S; AGUIAR, M. S. .Categorias ontológicas e afixos taxonômicos em línguas ameríndias. R. Científica UBM - Barra Mansa (RJ), ano XXVI, v. 23, n. 45, 2 . Sem. 2021 p. 26-36.

ISSN 1516-4071

costumam ser prototípicas, como acontece com o Tupi e com o Guarani antigos, que contavam com iwara, para cachorro, e com iwaraete, para a onça.

Em Tapirapé, o aumentativo foi acionado para promover a mesma diferenciação: xawãra significa 'cachorro', enquanto xawãroo (xawãra grande) equivale a 'onça'. Embora o aumentativo também apresente configurações prototípicas, é interessante observar que duas estratégias linguísticas diferentes estão em ação, para um único fenômeno, em línguas da mesma família. Ambas as estratégias têm, em comum, a não depreciação do animal exógeno e a consequente sublimação do animal nativo, algo que não ocorreu com outros bichos introduzidos pelos europeus. Na sequência, há outros exemplos do Guajajara.
(10a) Arapuha
'veado'
(10b) Arapuharana
'bode'

Novamente, entra em jogo a questão do animal nativo como modelo, que, porém, não é deslocado com um sufixo magnificador. Enquanto as similaridades entre o cachorro e o jaguar, que são de ordem ontológica, justificam a assimilação, pelo primeiro, do lugar ocupado pelo segundo, as similaridades entre o veado e o bode são aparentes - possivelmente, apenas morfológicas -, dando ao último certo aspecto deceptivo que nem sempre pode ser atribuído ao sufixo - rana.

Em resumo, processos de classificação observáveis por operações gramaticais ocorrem por meio de várias modalidades, desde a atribuição de traços distintivos de exemplares pertencentes a categorias gerais subespecificadas até procedimentos com noções ontológicas mais amplas, como a modulação de determinadas qualidades em relação a modelos prototípicos.

Diante de tal contextualização, pretende-se conhecer melhor o funcionamento dos modificadores na variante Mbya do Guarani ${ }^{4}$. Para tanto, partimos da identificação dos possíveis componentes linguísticos que se assemelhariam às palavras e aos afixos discutidos anteriormente. Analisamos, ao mesmo tempo, as noções semânticas envolvidas com os morfemas - que, inclusive, são usadas para descrever os diversos tipos de grafismo da etnia (BAPTISTA DA SILVA 2009); e a conceituação ontológica mobilizada, cujos fundamentos são encontrados nos mitos e na observação etnográfica.

${ }^{4}$ O Guarani, também integrante da Família Tupi-Guarani, têm, no Brasil, três variantes principais: o Mbya, o Nhandeva e o Kaiowá. Os indígenas, no entanto, as consideram línguas diferentes. O Kaiowá é uma das línguas ameríndias mais ativas no Brasil, com, aproximadamente, 45 mil falantes. As populações Guarani habitam as regiões Sul, Sudeste e Centro-Oeste do país. 
BONFIN, E.S; AGUIAR, M. S. .Categorias ontológicas e afixos taxonômicos em línguas ameríndias. R. Científica UBM - Barra Mansa (RJ), ano XXVI, v. 23, n. 45, 2 . Sem. 2021 p. 26-36.

ISSN 1516-4071

A cosmologia Guarani, em geral - e a Mbya, em especial -, apresenta uma grande riqueza terminológica no que diz respeito à esfera espiritual. Nesse contexto, os modificadores parecem assumir um papel importante para a compreensão dos tipos de entes da sobrenatureza e da cena cosmogônica originária. As obras etnográficas e linguísticas de Cadogan (1958; 2011) indicam termos que podem ser organizados em paradigmas, revelando a atuação de itens modificadores, como a diferenciação entre os seres do tempo mítico/originário, os seus reflexos atuais e outras relações, conforme apontam os dados abaixo.
(11a) mba'e
'ser'
(11b) mba'e rei rei
'seres vivos'
(11c) mba'e ete $\mathrm{i}$
'ser humano'
(11d) mba'e ypy
'seres originários’
(12a) mbói
'cobra'
(12b) mbói yma
'cobra originária'

Nimuendaju (1987), como Cadogan, afirma que a cor azul está ligada, também, a elementos míticos da época originária, criando nuances internas a esse conjunto.
(13a) jaguarete rekoypy
'jaguares originários mortais'
(13b) jaguarovy
‘jaguar azul mítico’

Nesse sentido, os termos prototípicos servem, como base, para as operações gramaticais e classificatórias realizadas pelos afixos taxonômicos. As versões exponenciadas do táxon são os exemplos mais usuais e podem envolver critérios cosmológicos que demonstram a concepção de sociabilidade estendida que é comum aos povos ameríndios. Por exemplo, há duas gradações exponenciadas para o termo "mata" em Guarani.
(14a) kaàguy
'mata'
(14b) kaàguy ete
'mata preservada
(14c) kaàguy puru ey 'mata pristina'

As traduções de (14b) e de (14c) procuram seguir as concepções Guarani sobre o grau de interferência humana no ambiente florestal. Portanto, a "mata de verdade" (kaàguy ete) é a 
BONFIN, E.S; AGUIAR, M. S. .Categorias ontológicas e afixos taxonômicos em línguas ameríndias. R. Científica UBM - Barra Mansa (RJ), ano XXVI, v. 23, n. 45, 2 . Sem. 2021 p. 26-36.

ISSN 1516-4071

ecologicamente conservada, enquanto a "mata mágica" (kaàguy poru ey), além de se manter preservada, está fora do alcance humano, por ser a morada das potências da sobrenatureza.

Assim, tais dados - que são ricos, apesar de estarem diversos em relatos etnográficos e em trabalhos linguísticos sobre o Mbya e sobre variantes próximas - sugerem a existência de um complexo sistema de modificadores, o qual parece ser sensível aos valores cosmológicos das etnias. Por isso, é necessário que sejam sistematizados e interpretados, à semelhança do que fizeram os trabalhos sobre os Ywalapiti e sobre os Xavante que citamos.

\section{CONSIDERAÇÕES FINAIS}

Não é comum que as análises linguísticas de cunho formal se evadam do âmbito estrutural e considerem aspectos extralinguísticos (SOUZA; AGUIAR, 2020). No caso da análise de línguas indígenas, esse procedimento se torna necessário, visto que seus sistemas, de alguma forma, são sensíveis a elementos de seu universo cultural.

Neste trabalho, destacamos, brevemente, como o sistema de modificadores de línguas ameríndias parecem depender, em parte, daquilo a que se referem em termos cosmológicos. Nesse sentido, defendemos que os morfemas negociam propriedades ontológicas dos itens a que se afixam. Demos o nome de modificadores ontológicos a esses morfemas e discutimos algumas de suas propriedades que nos pareceram mais relevantes.

\section{REFERÊNCIAS}

BAPTISTA DA SILVA, S. Iconografia e ecologia simbólica: retratando o cosmos guarani. In: PROUS, A.; LIMA, T.A. Ceramistas Tupiguarani. Brasília, DF: IPHAN, 2009.

BERLIN, B.; KAY, P. Basic color terms: Their universality and evolution. Berkeley; Los Angeles: University of California, 1969.

BONFIM, E.; QUINTINO, W. I'wamnari: as cores e a cosmologia Xavante. Revista FSA, Teresina, v. 10, n. 4, p. 290-303, out./dez. 2013.

CADOGAN, L. Ayvu Rapyta: textos míticos de los mbya-guarani del Guairá. São Paulo: USP, 1958.

Diccionario Mbya-Guarani Castellano. Assunción: CEADUC, 2011.

NIMUENDAJU, K. U. As lendas da criação e destruição do mundo como fundamentos da religião dos Apapocúva Guarani. São Paulo: USP, 1987.

NORDENSKIÖLD, E. Deductions suggested by the geographical distribution of some postcolumbian words used by the indians of South America. 1922. Disponível em: 
BONFIN, E.S; AGUIAR, M. S. .Categorias ontológicas e afixos taxonômicos em línguas ameríndias. R. Científica UBM - Barra Mansa (RJ), ano XXVI, v. 23, n. 45, 2 . Sem. 2021 p. 26-36. ISSN 1516-4071

http://etnolinguistica.wdfiles.com/local--files/biblio\%3Anordenskiold-1922deductions/nordenskiold 1922 deductions.pdf. Acesso em: 25 jun. 2021. 1986.

Línguas brasileiras: para o conhecimento das línguas indígenas. São Paulo: Loyola,

RODRIGUES, A. Relações Internas na Família Linguística Tupi-Gurani. Revista Brasileira de Linguística Antropológica, [S. l.], v. 3, n. 2, 2013. Disponível em:

https://periodicos.unb.br/index.php/ling/article/view/16264. Acesso em: 2 jul. 2021.

SOUZA, T. C. C. de; AGUIAR, M. S. Ensaio 12: Análise do Discurso e linguística indígena. In: Nascimento, L.; SOUZA, T. C. C. de. (Org.). Gramática(s) e Discurso(s): ensaios críticos. Campinas: Mercado de Letras, 2020, v. 1, p. 337-363.

VANDER VELDEN, F. F. Sobre cães e índios: domesticidade, classificação zoológica e relação humano-animal entre os Karitiana. Avá, Misiones, n.15, dez. 2009. Disponível em: https://www.redalyc.org/pdf/1690/169016753006.pdf. Acesso em: 25 jun. 2021.

VIVEIROS DE CASTRO, E. Os pronomes cosmológicos e o perspectivismo ameríndio. Mana, Rio de Janeiro, v. 2, n. 2, p. 115-44, 1996.

Esboço de cosmologia Ywalapíti. In: A inconstância da alma selvagem.

São Paulo: Cosac Naify, 2002. 